\title{
Conceivability and Possibility
}

\author{
Joshua Spencer
}

\section{Introduction}

Consider the following, simple, modal ontological argument:

1. It's possible that God exists.

2. If it's possible that God exists, then God exists.

3. So, God exists. ${ }^{1}$

A lot of interesting work in modal logic has been marshalled in defense of line (2). Here's the basic idea. Suppose it's necessary that if God exists, then God necessarily exists. Then, under the assumption that it's possible that God exists, it follows it's possible that God necessarily exists. But, here's where the modal logic comes in handy, if it's possible that God necessarily exists, then God necessarily exists; and if God necessarily exists, then God just flat out exists. So, from our assumption that it's possible God exists, it follows that God exists. Hence, line (2).

What about line (1)? Why should anyone believe it's possible that God exists? Here's one answer: we should believe it's possible that God exists because we can conceive that God exists. In this paper, I will be exploring the connection between conceivability and possibility, and support from conceivability for the argument presented above. Here's how the paper will be structured. In section 2 , I will characterize the notion of conceivability by

\footnotetext{
${ }^{1}$ A more complex variant of the modal ontological argument is developed by Hartshorne (1965), Malcolm (1960), and Plantinga (1974). The argument is further discussed by Oppy (1995), (2016), and by van Inwagen (1977) and (2015).
} 
comparing it to perceivability. In section 3, I will consider analyses of conceivability in terms of imagination. In section 4, I will consider analyses in terms of conceptual coherence. Finally, in section 5, I will look at the prospects of supporting the modal ontological argument through conceivability.

\section{Conceivability and Perceivability}

Some people take the fact that one conceives a proposition as a premise in a little argument for the conclusion that that proposition is possible. Others take the fact that one conceives a proposition to constitute prima facie evidence for the possibility of that proposition. In this paper, I will be interested in the latter of these approaches. I find it fruitful, on the latter approach, to investigate another evidence-constituting mental state. Specifically, I find it fruitful to investigate perceivability in order to learn what an adequate theory of conceivability (as an evidence-constituting mental state) must look like.

The claim that something is perceivable may be taken in one of two ways. First, it may be taken as the claim that someone, either a particular someone or someone in general, is able to perceive it. On this way of taking the claim, our attention should properly be focused on subjects (i.e. perceivers) and their mental states of perceiving. We should be seeking to characterize and analyze the mental state of perceiving and asking what it is about various perceivers that makes them able to grasp objects by way of that mental state. Alternatively, it might be taken as the claim that something is apt to be perceived. On this way of taking the claim, our attention should properly be focused on the objects of perception (which, for simplicity, we will take to be states of affairs). We should be asking 
what it is about various objects that makes them apt to be grasped by way of that mental state. $^{2}$

Focus on the subject side of perception for a moment. Note that perceptions can go awry. There's a difference between perceiving and misperceiving. Presumably a misperceiving occurs when someone has nearly everything that it takes to be perceiving, but somehow or other gets things wrong. Let's say that when someone, S, is in a mental state as if $\mathrm{S}$ were perceiving $\mathrm{O}$ being $\mathrm{F}$, then $\mathrm{S}$ perceives $\mathrm{O}$ being $\mathrm{F}$ only if it is actually the case that $\mathrm{O}$ is $\mathrm{F}$. On the other hand, when $\mathrm{S}$ is in a sensory state as if $\mathrm{S}$ were perceiving $\mathrm{O}$ being $\mathrm{F}$, if it's not actually the case that $\mathrm{O}$ is $\mathrm{F}$, then $\mathrm{S}$ misperceives $\mathrm{O}$ being $\mathrm{F} .^{3}$

Focus, now, on the object side of perception. Some states of affairs are apt to be perceived and others are not. The state of affairs of three being prime just isn't apt to be perceived. It involves an abstract object rather than a concrete object and it involves a feature that cannot be detected via sensory perception. But what about states of affairs that do involve concrete things and that $d o$ involve features that can be detected by sensory perception? Are all of those states of affairs apt to be perceived? Probably not. The state of affairs of Wesley (my cat) being orange is apt to be perceived. It's apt to be perceived partly because Wesley is in fact orange. The state of affairs of Wesley being grey, if it exists, is not apt to be perceived. That's because Wesley just isn't grey. Of course, if Wesley had been

\footnotetext{
${ }^{2}$ A similar distinction appears in Aquinas, clearly stated in Expositio Super Librum Boethii De Trinitate, q. 4, a. 3, ad 1 (p. 151). The distinction also appears in Scotus, where it is most clearly stated in Lectura II, Dist. 3, pars. 1, Q 5-6, n. 180. In Lectura II, Scotus says "... the fact that [the singular] is not understood per se by our intellect is not due to the singular itself but to the imperfection of our intellect; in the same way the fact that the owl does not see the sun is not due to the sun itself, but to the owl." Thanks to Fabrizio Mondadori for translating this passage.

${ }^{3}$ It isn't obvious to me what the difference is between a misperception and a hallucination. For the remainder of this paper, I will be ignoring this distinction.
} 
grey, then the state of affairs of Wesley being grey would have been apt to be perceived. But that isn't enough to make it actually apt to be perceived.

Now let's turn to conceivability. Just as with perceivability, the claim that something is conceivable may be taken in one of two ways. First, it may be taken as the claim that someone, either a particular someone or someone in general, is able to conceive it. On this way of taking the claim, our attention should properly be focused on subjects (i.e. conceivers) and their mental states of conceiving. We should be seeking to characterize and analyze the mental state of conceiving and asking what it is about various conceivers that makes them able to grasp objects by way of that mental state. Alternatively, it might be taken as the claim that something is apt to be conceived. On this way of taking the claim, our attention should properly be focused on the objects of conceiving (i.e. propositions). We should be asking what it is about various objects that makes them apt to be grasped by way of that mental state.

Focus on the subject side for a moment. Note that conceiving can go awry. There's a difference between conceiving and misconceiving. Presumably a misconceiving occurs when someone has nearly everything that it takes to be conceiving, but somehow or other gets things wrong. Let's say that when someone, $\mathrm{S}$, is in a mental state as if $\mathrm{S}$ were conceiving that $\mathrm{O}$ is $\mathrm{F}$ then $\mathrm{S}$ conceives that $\mathrm{O}$ is $\mathrm{F}$ only if it's possible that $\mathrm{O}$ is $\mathrm{F}$. On the other hand, when $\mathrm{S}$ is in a sensory state as if $\mathrm{S}$ were conceiving that $\mathrm{O}$ is $\mathrm{F}$, if it impossible for $\mathrm{O}$ to be $\mathrm{F}$, then $\mathrm{S}$ misconceives that $\mathrm{O}$ is $\mathrm{F}$. But if all of that is true, then someone is able to conceive a proposition only if it is possible.

Focus, now, on the object side of conceiving. Are all propositions apt to be conceived? Probably not. Although some impossible propositions would be apt to be 
conceived if they were possible, it seems plausible that a proposition is apt to be conceived only if it is in fact possible. We again have, then, that a proposition is conceivable only if it is possible.

So, from the subject side of things, we have that someone conceives (rather than misconceives) a proposition only if it is possible. And from the object side of things, we have that a proposition is apt to be conceived by someone only if it is possible. So, we will take this as our first constraint on an adequate account of conceivability.

The Representation Constraint:

If $\mathrm{S}$ conceives that $\mathrm{P}$, then $\mathrm{P}$ is possible. ${ }^{4}$

Now, let's briefly return to perceiving. When someone, S, perceives $\mathrm{O}$ being $\mathrm{F}$, then $\mathrm{S}$ is prima facie reasonable in believing that $\mathrm{O}$ is $\mathrm{F}$. After all, there is an explanatory connection between an actual state of affairs and S's perceiving; the state of affairs causes S's perceiving. Moreover, this causal connection is underwritten by a law-like pattern between actual states of affairs of a particular type and perceivings of a particular type. The causal connection which is underwritten by a law-like pattern partly grounds that $\mathrm{S}$ is prima facie reasonable in believing that $\mathrm{O}$ is $\mathrm{F}$ when $\mathrm{S}$ perceives $\mathrm{O}$ being $\mathrm{F}$.

\footnotetext{
${ }^{4}$ Stephan Yablo (1993) considers a similar constraint. But since he assumes that conveivings can be fallible, he suggests that the veracity condition for conceiving includes the possibility of what is conceived. So, according to Yablo, if I conceive that $\mathrm{P}$, then my conceiving that $\mathrm{P}$ is veridical only if $\mathrm{P}$ is in fact possible. Most of what I say below could be said if the constraint were stated as a veracity condition rather than a necessary condition on conceiving itself.
} 
Similarly, if conceivability generates reasonable belief in possibility, then when S conceives that $\mathrm{P}, \mathrm{S}$ is prima facie reasonable in believing that $\mathrm{P}$. We'll take this to be the second constraint on an adequate theory of conceivability.

The Epistemic Constraint:

If $\mathrm{S}$ conceives that $\mathrm{P}$, then $\mathrm{S}$ is prima facie reasonable in believing that $\mathrm{P}$ is possible. ${ }^{5}$

And, on an adequate theory of conceivability, there should be an explanatory connection between the possible truth of a proposition and one's conceiving that proposition; an explanatory connection that partly grounds that $\mathrm{S}$ is prima facie reasonable in believing that $\mathrm{P}$ is possible when $\mathrm{S}$ conceives that $\mathrm{P}$. We'll take this to be the third constraint on an adequate theory of conceivability.

The Explanatory Constraint:

If $\mathrm{S}$ conceives that $\mathrm{P}$, then there is an explanatory connection between the fact that $\mathrm{P}$ is possible and the fact that $S$ conceives that $P$.

This third constraint is probably the most difficult to accommodate. It is highly implausible that facts about what is possible cause facts about what various people conceive. What seems more likely is that whatever grounds that $\mathrm{P}$ is possible also grounds that $\mathrm{S}$ is able to conceive that $P$.

${ }^{5}$ One might also hold that if $\mathrm{S}$ is in a mental state as if $\mathrm{S}$ were conceiving that $\mathrm{P}$, then $\mathrm{S}$ is prima facie reasonable in believing that $\mathrm{P}$ is possible. This would allow one to be reasonable in believing that $\mathrm{P}$ is possible even when one has misconceived that $\mathrm{P}$. 
Let's keep each of these constraints in mind as we consider two of the most

plausible and best defended approaches of conceivability. We'll say that any notion of

conceivability that satisfies these three constraints is a notion of philosophical

conceivability.

\section{Conceivability as Imaginability}

Some people try to assimilate conceivability and imaginability. Stephen Yablo (1993) for

example, defends the following account of conceiving: 6

\section{The First Imagination Account:}

S conceives that $\mathrm{P}$ iff $\mathrm{S}$ imagines a world, $\mathrm{w}$, such that $\mathrm{S}$ takes $\mathrm{w}$ to verify that $\mathrm{P} .^{7}$

So, on this view, if I imagine a world such that I take to it verify that some lions have stripes,

I thereby conceive that some lions have stripes. I imagine such a world, presumably, by

"seeing with my mind's eye" or "hearing with my mind's ear" or by any other kind of what

${ }^{6}$ Others who defend views on which conceiving is a type of imagining include Gregory (2010), Ichikawa and Jarvis (2012), and Kung (2010), (2016). Though Ichikawa and Jarvis should perhaps more properly be thought of as conceptual coherence theorists. Critics of conceiving as imagining include Roca-Royes (2011), Tidman (1994), and van Inwagen (1998).

7 Three minor comments are in order about Yablo's thesis. First, it is unclear why it must be a world that is imagined rather than just an object. After all, Yablo explicitly says that one need not imagine a whole world in order to imagine a world. For example, one could imagine a world in which a lion has stripes simply by imagining a lion with stripes. But, then, it isn't clear why it's important to imagine the world rather than just the lion. Second, whether or not someone takes something to verify a proposition seems to me epistemically irrelevant. A religious fanatic might irrationally take geopolitical events to verify that the end is nigh, but that doesn't make the fanatic rational in believing that the end is nigh. And, third, it seems that 'verify' is too strong of a word. After all, 'verify' is a success term. If something verifies that $\mathrm{P}$, then it is in fact the case that $P$. But the presence of a particular object in one's experience might give one evidence that $P$ without verifying that $\mathrm{P}$ (and without one taking the presence in experience to verify that P). Similarly, the presence of an object in one's conceiving or imagining might give one evidence that $\mathrm{P}$ is true in one's conceiving without verifying that $\mathrm{P}$ (and without one taking the presence in the conceiving or imagining to verify that $\mathrm{P}$ in the conceiving/imagining). 
we might call "sensory imaginings". However, Yablo is clear that one need not imagine oneself, or anyone else, having an experience in the imagined world. So, I imagine a world such that I take it to verify, from the outside so to speak, that some lions have stripes; I need not imagine a world in which I or anyone else has an experience of striped lions or of anything. Yablo is also clear that one need not imagine a world in complete detail or in its entirety. So, when I imagine a world such that I take it to verify that some lions have stripes, I need not imagine the particular numbers of stripes that various lions have. That's just more detail than is necessary. I just need to imagine lions with some number of stripes or other. Moreover, I need not imagine either the presence or non-presence of a kangaroo in the Woodland Park Zoo. That's a portion of the world that I can just safely ignore.

\subsection{The Imagination Account and the Representation Constraint}

One standard objection to The First Imagination Account is that we can imagine worlds that we take to verify propositions that are impossible. For example, we can imagine a world in which mathematicians announce that they have discovered and verified a proof of Goldbach's Conjecture. We would take this world to verify that Goldbach's Conjecture is true. Likewise we can imagine a world in which those same mathematicians announcing in the same circumstances that they have discovered and verified that there is a counterexample to Goldbach's Conjecture. We would take this world to verify that Goldbach's Conjecture is false. Since Goldbach's Conjecture is necessarily true if true at all and necessarily false if false, we have conceived in one of these situations of something that happens to be impossible. 
Most straightforwardly, this objection is meant to show that The Imagination Account fails to capture philosophical conceivability because it fails to meet The Representation Constraint. But since The Representation Constraint is generated from both the objective side of conceivability and from the subjective side of conceivability, there are actually two problems here. What this means is that The Imagination Account both fails to distinguish between those propositions that are apt to be conceived and those that are not, but also fails to distinguish between someone who is conceiving and someone who is misconceiving.

One thing to note about The First Imagination Account is that the object of imagination is a world rather than a possible world. One might think, then, that the following simple modification will help to align the account with The Representation Constraint:

The Second Imagination Account:

$S$ conceives that $P$ iff $S$ imagines a possible world, $w$, such that $S$ takes $w$ to verify that $P$.

But this modification seems to put the view in tension with The Epistemic Constraint. For, arguably, one cannot imagine an F without first having enough knowledge of Fs to guide one's imaginative activity; without knowing enough to imagine an F rather than something else. For example, one cannot imagine a television news report such that one takes it to verify that the end is nigh without first having enough knowledge of televisions news reports to guide one's imaginative activity. If I imagine such a news report, then I must 
know enough to imagine a television news report verifying that the end is nigh rather than a television production of War of the Worlds. It is partly because I already know what a television news report looks like that I can imagine one verifying that the end is nigh.

Similarly, if I imagine a possible world, $\mathrm{w}$, such that I take w to verify that the end is nigh, I must first have enough knowledge of possibility to guide my imaginative activity. I must know enough to imagine a possible world rather than an impossible world. But if I know enough to imagine a possible world such that I take it to verify that the end is nigh, then I must already know it's possible for the end to be nigh. Hence, the imaginative experience cannot make me prima facie reasonable in believing it's possible that the end is nigh. Hence, The Second Imagination Account violates The Epistemic Constraint. ${ }^{8}$ What we need, clearly, is not a restriction on the object of imagination, but rather a separate condition on conceivability.

The Third Imagination Account:

$\mathrm{S}$ conceives that $\mathrm{P}$ iff (i) $\mathrm{S}$ imagines a world, $\mathrm{w}$, such that $\mathrm{S}$ takes $\mathrm{w}$ to verify that $\mathrm{P}$ and (ii) $\mathrm{P}$ is possible.

\footnotetext{
${ }^{8}$ One might respond to my objection by claiming that imagination is not constrained in the way I am suggesting. Perhaps, the responder says, one can imagine one's television as a toaster or one's cat as a dog. Hence, perhaps one can imagine a possible world as any number of ways without knowing that those ways of imagining that world are possible. Unfortunately, if we are so unconstrained, then we can imagine all sorts of possible worlds in impossible ways. I can imagine a possible world as a world in which water is composed of $\mathrm{XYZ}$ rather than $\mathrm{H} 2 \mathrm{O}$. Hence, I can imagine a possible world such that I take it to verify that water is composed of XYZ. Of course, I wouldn't be imagining a possible world as any possible world is, but neither am I imagining a cat as any cat is when I imagine a cat as a dog. If imagination is not constrained, then according to The Second Imagination Account, I can conceive that water is composed of XYZ. Hence I can conceive of an impossibility and The Second Imagination Account is, again, in violation of The Representation Constraint.
} 
As I mentioned above, there are two problems for imagination accounts associated with The Representation Constraint. One problem has to do with the fact that any adequate account of conceiving must distinguish propositions that are apt to be conceived from those that are not. The Third Imagination Account avoids this problem by making it explicit that a proposition can be conceived only if it is possible. What makes a proposition apt to be conceived, then, is that it is possible (or that it has whatever grounds its possibility). But the second problem associated with The Representation Constraint is that any adequate account of conceiving must distinguish those who are conceiving from those who are misconceiving. The Third Imagination Account falls to this second problem.

Intuitively, one misconceives that $\mathrm{P}$ when one has nearly everything that it takes to be conceiving, but somehow or other gets things wrong. But if that's right, then given The Third Imagination Account, one misconceives that $\mathrm{P}$ when one imagines that $\mathrm{P}$ and yet $\mathrm{P}$ is impossible. But it seems like we can imagine impossible things without thereby misconceiving. For example, when I am watching Game of Thrones, I am imagining a world and I take that imaginative world to verify that there are dragons. If, as many contemporary philosophers believe, dragons are impossible, then I am imagining an impossibility. But I have not thereby misconceived. After all, I am not engaged in any epistemic endeavor at all. Hence, I have not done anything epistemically awry and, in particular, I have not mistakenly conceived or misconceived. If I have not misconceived when I imagine an impossibility, then The Third Imagination Account is mistaken. ${ }^{9}$

\footnotetext{
${ }^{9}$ Here is a related objection. The conditions under which one has made a mistake in conceiving are very different from the conditions under which one has made a mistake in imagining. Mistakes in conceiving are grounded in different norms than mistakes in imagining. When I watch the Star Trek episode $A$ Piece of the Action, I make a mistake in imagining if I imagine that Captain Kirk and company are gangsters in Chicago during the 1920s rather than space explorers from the future. But the imagining is a mistake because one ought to imagine that $\mathrm{P}$ when viewing a television program that depicts that $\mathrm{P}$. When it comes to conceiving,
} 
Here is a simple modification that will avoid this problem:

The Fourth Imagination Account:

$\mathrm{S}$ conceives that $\mathrm{P}$ iff (i) $\mathrm{S}$ aims to discover what is possible by way of imagination,

(ii) $\mathrm{S}$ imagines a world, $\mathrm{w}$, such that $\mathrm{S}$ takes $\mathrm{w}$ to verify that $\mathrm{P}$, and (iii) $\mathrm{P}$ is possible.

When one's aim is to discover what is possible by way of imagination, then (arguably) one makes a mistake when one imagines something that is impossible. Hence, The Fourth Imagination Account avoids violating The Representation Constraint even when the constraint is considered from the subject side.

\subsection{The Imagination Account, The Explanatory Constraint, and The Epistemic Constraint}

The Imagination Account must also satisfy The Explanatory Constraint and the Epistemic Constraint in order to be a viable account of philosophical conceivability. It doesn't seem like an implausible hypothesis that given any sensory imagining one can have, there is something in it that's possible. Specifically, given any sensory imagining one can have, the distribution of sensory qualities that are imagined is possible. ${ }^{10}$ In this way, one might argue, The Imagination Account does in fact satisfy The Explanatory Constraint. After all, the necessary connection between sensory imaginings and possible distributions of

on the other hand, we are following a different norm: one ought to conceive only what is possible. Hence, a mistake in conceiving and a mistake in imagining are violations of different norms and, so, The Third Imagination Account is mistaken.

10 One might object that I can see with my mind's eye Escher's waterfall, but that that does not correspond to any possible distribution of sensory qualities. However, Shigeo Fukuda is a Japanese artist who has made three dimensional models of some of Escher's drawings, including the waterfall. When viewed from a certain angle, one has a visual experience that matches the visual experience one has when looking at Escher's drawing. So, arguably, there is a possible distribution of sensory qualities corresponding to each sensory imagining. For a more elaborate defense of this general claim see Sorensen (2006). 
sensory qualities might partly ground that one is prima facie reasonable in believing something is possible when one is conceiving.

Let's suppose that there is something possible in each sensory imagining. Then it seems plausible that one who is imagining is thereby prima facie reasonable in believing in the possibility of something in that imagining. But what, exactly, is one prima facie reasonable in believing? Some might claim that one is prima facie reasonable in believing only in what, in general, is possible in imaginings. Since the distributions of sensory qualities are what, in general, is possible in imaginings, it would follow that one is only reasonable in believing in the possibility of propositions about those distributions. ${ }^{11}$ of course, this requires a further modification of The Imagination Account:

The Fifth Imagination Account:

$\mathrm{S}$ conceives that $\mathrm{P}$ iff (i) $\mathrm{S}$ aims to discover what is possible by way of imagination, (ii) $\mathrm{S}$ imagines a world, $\mathrm{w}$, such that $\mathrm{S}$ takes $\mathrm{w}$ to verify $\mathrm{P}$, where (iii) $\mathrm{P}$ is about the distribution of sensory qualities imagined in $\mathrm{w}$, and (iv) $\mathrm{P}$ is possible.

So, on this variant, one can conceive only of propositions about distributions of sensory qualities (or propositions that are supported by propositions about such distributions). Since those propositions are guaranteed to be possible, given the explanatory connection noted above, The Fifth Imagination Account arguably satisfies The Epistemic Constraint.

\footnotetext{
11 Or, perhaps a bit less narrowly, one might prima facie reasonably believe in the possibility of certain more substantive propositions as long as such a proposition is supported by a propositions about the distribution of sensory qualities in an imagining. Gregory (2010) and Kung (2010) both defend something like this variant of The Imagination Account, though their variants are more sophisticated along a number of dimensions.
} 
Recall the example of Goldbach's Conjecture. I can aim to discover what is possible by way of imagination while imagining a world, $w$, in which mathematicians announce that they have discovered and verified a proof of Goldbach's Conjecture. I can also aim to discover what is possible by way of imagination while imagining a world, $w$, in which mathematicians announce that they have discovered and verified the existence of a counterexample of Goldbach's Conjecture. Ordinarily, I might take the first imagined world to verify that Goldbach's Conjecture is true and the second to verify that Goldbach's Conjecture is false. So, on The Fourth Imagination Account, I have nearly all it takes to conceive that Goldbach's Conjecture is true and nearly all it takes to conceive that Goldbach's Conjecture is false. But, given The Fifth Imagination Account, I can conceive by way of these imaginings only that it appears as if mathematicians are making certain announcements, i.e. that there are distributions of sensory qualities as if there were mathematicians making certain announcements.

The suggestion above has its advantages. But a defender of The Imagination Account might resist any further modification. After all, since a necessary condition on conceiving a proposition, given The Fourth Imagination Account, is that the proposition in question is possible, then even though one can imagine both a world such that one takes it to verify Goldbach's Conjecture and another world such that one takes it to verify the negation of Goldbach's Conjecture, only one of these imaginings can constitute a genuine conceiving. Moreover, if one were in fact looking at some mathematicians announcing a proof of Goldbach's Conjecture, then one would thereby be reasonable in believing that Goldbach's Conjecture is true. Similarly, if one were to imagine some mathematicians making such an announcement, then one might thereby be reasonable in believing that Goldbach's 
Conjecture is possibly true. So, one might think, even The Fourth Imagination Account satisfies The Epistemic Constraint.

However, I think there's a difference between perceiving Goldbach's Conjecture being true on the one hand and having a perceiving which provides evidence of Goldbach's Conjecture. One cannot plausibly perceive Goldbach's Conjecture being true since one cannot perceive mathematical states of affairs. So, in the case above, one has not perceived Goldbach's Conjecture being true but merely had a perceiving that, in the right circumstances, provides evidence in favor of Goldbach's Conjecture. Moreover, it provides evidence merely because of contingent facts connecting perceptions of mathematicians making announcements about mathematical results and the truth of those results.

Similarly, there's a difference between conceiving that Goldbach's Conjecture is true on the one hand and having a conceiving which, in the right circumstances, provides evidence in favor of the possibility of Goldbach's Conjecture. Arguably, in the case above, no one has conceived of Goldbach's Conjecture being true. Perhaps one has had a conceiving that provides evidence for the possibility of Goldbach's Conjecture. But If it does provide evidence, then it does so because of contingent facts connecting one's conceiving of mathematicians making announcements about mathematical results and the possible truth of those results. The Fifth Imagination Account can make sense of this distinction and The Fourth cannot.12

\footnotetext{
12 Another reason some might favor The Fifth Account over The Fourth Account is that on The Fifth Account it may be transparent to the imaginer that that which is imagined is thereby conceived. For, suppose that I am aiming to discover what's possible by way of imagination while imagining a world in which mathematicians announce that they have discovered and verified a proof of Goldbach's Conjecture. On the Fifth Imagination Account, I can thereby conceive only that it appears as if mathematicians are announcing the proof of Goldbach's Conjecture and, as long as I know what it takes to conceive, I can recognize that I am conceiving rather than misconceiving. However, if The Fourth Imagination Account were true, then I can be in a mental state as if I were conceiving that Goldbach's Conjecture is true and, if it happens to be possibly true, then I
} 


\section{Conceivability and Conceptual Consistency}

The explanatory connection between possibility and conceivability on The Fifth

Imagination Account is very weak. Some might think that the mere necessary connection

between sensory imaginings and possible distributions of sensory qualities is insufficient

for generating prima facie reasonable belief in possibilities. The Conceptual Account of

conceivability might provide a stronger explanatory connection if conceptual consistency is

a partial grounds for possibility.

Here's an initial idea. Let "Modal Conceptualism" be the thesis that $\mathrm{P}$ is necessary iff and because $\mathrm{P}$ is a conceptual truth. ${ }^{13,14}$ Then $\mathrm{P}$ is possible iff and because $\mathrm{P}$ is consistent with all conceptual truths. We may then give the following account:

The Initial Conceptual Account

$\mathrm{S}$ conceives that $\mathrm{P}$ iff $\mathrm{S}$ knows that $\mathrm{P}$ is consistent with all conceptual truths. ${ }^{15}$

would have thereby conceived it. But, in some sense, I won't be able to recognize that I have conceived rather than misconceived. After all, on The Fourth Account, whether I have conceived rather than misconceived has everything to do with whether or not Goldbach's Conjecture is in fact possibly true.

${ }^{13}$ I assume, here and throughout the rest of the essay, that any truth that follows from solely conceptual truths is itself a conceptual truth.

${ }^{14}$ Traditional Conventionalism is the conjunction of three theses: (i) For any p, p is necessary iff and because $p$ is analytic, (ii) for any $p, p$ is a priori knowable iff and because $p$ is analytic, and (iii) for any $p, p$ is analytic iff and because there is a sentence, $S$, that expresses $p$ and $S$ is true solely in virtue of the conventions of our language. See Ayer (1936) for a succinct statement. See Sider (2003) for a detailed critical discussion. The view I am considering in the text is slightly different from Traditional Conventionalism. First, although all analytic truths are conceptual truths, it is not the case that all conceptual truths are analytic. Second, I take no stand on whether or not either analytic truths or conceptual truths are true because of the conventions of our language. It is perfectly consistent with the view expressed in the text, for example, that conceptual truths are brute facts.

${ }^{15}$ Gendler and Hawthorne (2002) consider an account of conceivability similar to the one above which assumes that all necessary truths are a priori knowable. 
Given Modal Conceptualism and The Initial Conceptual Account, the fact that a proposition is consistent with all conceptual truths is a partial grounds for the fact that it is possible and for the fact that it is conceivable. Hence, there is a tight explanatory connection between conceivability and possibility and The Explanatory Constraint is met. Since something is possible because it is consistent with all conceptual truths, if someone knows that it is consistent with all conceptual truths, then she is in a position to know that it is possible. Hence, the Epistemic Constraint is met. And, finally, since knowledge entails truth, if someone knows that a proposition is consistent with all conceptual truths, it is in fact consistent with all conceptual truths and hence, given Modal Conceptualism, is possible. So, the view satisfies the Representational Constraint.

\subsection{Sophisticated Modal Conceptualism}

Unfortunately, Modal Conceptualism is false. In the latter half of the $20^{\text {th }}$ century, metaphysicians became more comfortable with certain necessities that seem to be nonconceptual. For example, it is often accepted that water is necessarily composed solely of the chemical elements hydrogen and oxygen. But, of course, it's not conceptually true that water is composed solely of those chemical elements. Hence, some necessary truths are not conceptual truths. ${ }^{16,17}$

\footnotetext{
${ }^{16}$ Early discussions of these necessities include Kripke (1971), (1980), and Putnam (1975). They, however, were not focused on whether or not these propositions are conceptual truths. Other examples of necessary truths that are not conceptual might include the propositions that Sasha Obama's parents are Barack and Michelle Obama, that gold has atomic number 79, and that pain is intrinsically bad.

${ }^{17}$ Putnam (1975) briefly argues that conceivability is not a guide to possibility on the grounds that one might conceive of these necessities being false. Putnam, though, seems to be assuming something like the first imagination account of conceivability. As we have already seen, plausible imagination accounts are more sophisticated.
} 
A variant of Modal Conceptualism can accommodate these necessary truths that are non-conceptual. Although it's not conceptually true that water is composed solely of chemical elements hydrogen and oxygen, it might be conceptually true that if water is in fact solely composed of certain chemical elements, then water is necessarily solely composed of those chemical elements. This conceptual truth, when combined with the nonconceptual truth that water is in fact solely composed of hydrogen and oxygen, entails that water is necessarily solely composed of hydrogen and oxygen. This suggests a variant of Modal Conceptualism on which all necessary truths can be traced back to conceptual truths. Let "Sophisticated Modal Conceptualism" be the view that if something is a necessary truth, then either (i) it is necessary because it is conceptual or (ii) it is a necessary truth that follows ampliatively from a conceptual truth in conjunction with some non-conceptual truths. So, for example, the proposition that all blue things are extended is necessary because it is conceptual. But the proposition that water is necessarily composed of hydrogen and oxygen follows ampliatively from a conceptual truth and a non-conceptual truth; in particular, it follows from the conceptual truth that if water is in fact solely composed of certain chemical elements, then water is necessarily solely composed of those chemical elements, along with the proposition that water is in fact composed of hydrogen and oxygen. On this view, all necessary truths trace their necessity back to conceptual truths in one of these two ways. ${ }^{18}$

\footnotetext{
18 This view is very similar to the view advocated by Alan Sidelle (1989). However, again, Sidelle focused on analytic truths instead of conceptual truths. Moreover, I take no stand on what grounds conceptual truths if anything. In particular, I take no stand on whether conceptual truths are grounded in either linguistic conventions, a priori conditions of cognition, or anything else thinker centric. For example, it is consistent with the view as I have presented it that for each conceptual truth, it's a brute fact that it is a conceptual truth.
} 
Now we can distinguish between two types of possibility. Let's say a proposition is conceptually possible iff it is consistent with all conceptual truths. And a proposition is metaphysically possible iff it is consistent with all conceptual truths together with those truths which, when combined with conceptual truths, ampliatively generate necessities. So, since it is consistent with all conceptual truths that water is solely composed of chemical elements other than hydrogen and oxygen, it is conceptually possible that water is solely composed of chemical elements other than hydrogen and oxygen. But, since it ampliatively follows from a conceptual and non-conceptual truth together that water is necessarily solely composed of hydrogen and oxygen, it isn't metaphysically possible for water to be composed solely of chemical elements other than hydrogen and oxygen.

Is there, one might ask, any connection between conceptual possibility and metaphysical possibility? Maybe. But I have to admit we're about to enter a rather dubious philosophical realm. Some people think that every conceptually possible proposition characterizes a genuine metaphysical possibility. So, consider the proposition that water is solely composed of chemical elements other than hydrogen and oxygen. Although this proposition isn't metaphysically possible, it is conceptually possible and hence might characterize a metaphysical possibility even though it doesn't express a metaphysical possibility. It might characterize the possibility in which the liquid that fills our lakes and oceans is solely composed of chemical elements other than hydrogen and oxygen. For, there's some sense on which, prior to our investigations into its chemical composition, water "could have turned out" to be so composed of elements other than hydrogen and oxygen. 
Here's one way to make sense of all of this. Suppose the proposition that water is solely composed of chemical elements hydrogen and oxygen is identical to a certain descriptive proposition. For the sake of brevity, we'll say that it is identical to the proposition that the actual watery substance is solely composed of chemical elements hydrogen and oxygen. But the concept of being actual has two dimensions to it. Consider the proposition that if Obama had lost the 2012 election, then we would have actually had a Republican president in 2013. That proposition has two dimensions of evaluation. Let's look at this given a nearest-worlds account of counterfactuals. First, the counterfactual might be evaluated as true since in the nearest world at which Obama loses the 2012 election, Romney is elected president and so in that world there is a Republican president in 2013. For, along this dimension, that alternative world is taken as actual. However, the counterfactual might be evaluated as false since even though there is a nearby world at which Obama loses the 2012 election, still in this world Obama won and we do not have a Republican president. Along this dimension, our world is taken as actual. Each proposition containing the concepts of being actual, then, must be evaluated at a pair of worlds, one of which is the world taken as actual and the other of which is the world taken as counterfactual.

Let's go back to our watery example and let's suppose our world is taken as actual. The water substance in our world happens to be composed of hydrogen and oxygen. Moreover, that very substance will be composed of hydrogen and oxygen in any world in which it is found. So, the proposition that water is composed of hydrogen and oxygen (i.e. the proposition that the actual watery substance is composed of hydrogen and oxygen) is necessary. This can be represented in the two dimensional chart below where, let's just 
stipulate, the watery substance in $\mathrm{W} 1$ is $\mathrm{H} 2 \mathrm{O}$ and the watery substance in $\mathrm{W} 2 \mathrm{is} \mathrm{H} 2 \mathrm{O}$, but the watery substance in W3 has some other chemical composition, XYZ. In the first row, W1 is taken as actual and the watery substance in W1 happens to be composed solely of Hydrogen and oxygen. So, it doesn't matter which world we consider as counterfactual in that row, since the watery substance in $W 1$ is solely composed of hydrogen and oxygen, it will be true in those worlds that any substance that is an actual watery substance is composed solely of hydrogen and oxygen.

\begin{tabular}{|c|l|l|l|l|}
\hline \multirow{2}{*}{$*$} & \multicolumn{4}{|c|}{ World taken as Counterfactual } \\
\hline \multirow{4}{*}{$\begin{array}{c}\text { World taken as } \\
\text { actual }\end{array}$} & W1 & W1 & W2 & W3 \\
\cline { 2 - 6 } & W2 & T & T & T \\
\cline { 2 - 6 } & W3 & & & \\
\hline
\end{tabular}

*Partial chart for the proposition that the actual watery substance is composed solely of chemical elements hydrogen and oxygen (i.e. water is composed solely of chemical elements hydrogen and oxygen).

Similarly, if W2 were taken as actual, then no matter which world is taken as counterfactual, the actual water substance, i.e. the substance that is the watery substance in W2, is composed solely of hydrogen and oxygen. However, if W3 is taken as actual, then no matter which world is taken as counterfactual, the actual water substance, i.e. the substance that is the watery substance in $\mathrm{W} 3$, is composed solely of $\mathrm{XYZ}$ and not hydrogen and oxygen. So, we can complete the chart as follows:

\begin{tabular}{|l|l|l|l|l|}
\hline \multirow{2}{*}{$* *$} & \multicolumn{4}{|c|}{ World taken as Counterfactual } \\
\hline \multirow{3}{*}{ World taken as } & & W1 & W2 & W3 \\
\cline { 2 - 6 } & W1 & T & T & T \\
\hline
\end{tabular}




\begin{tabular}{|l|l|l|l|l|}
\hline actual & W2 & T & T & T \\
\cline { 2 - 5 } & W3 & F & F & F \\
\hline
\end{tabular}

${ }^{* *}$ Complete chart for the proposition that water is composed solely of chemical elements hydrogen and oxygen (i.e. water is composed solely of chemical elements hydrogen and oxygen)

But if each counterfactual world is itself taken as actual, then the proposition is contingent since there are some worlds such that the substance that is the watery substance in those worlds is solely composed of chemical elements other than hydrogen and oxygen. This is represented by the truth values along the diagonal:

\begin{tabular}{|c|l|l|l|l|}
\hline \multirow{2}{*}{$* * *$} & \multicolumn{5}{|c|}{ World taken as Counterfactual } \\
\hline \multirow{4}{*}{$\begin{array}{c}\text { World taken as } \\
\text { actual }\end{array}$} & & W1 & W2 & W3 \\
\cline { 2 - 6 } & W1 & T & T & T \\
\cline { 2 - 6 } & W3 & T & T & T \\
\cline { 2 - 6 } & W3 & F & F & F \\
\hline
\end{tabular}

***Complete chart for the proposition that the actual watery substance is composed solely of chemical elements hydrogen and oxygen (with diagonal bolded).

This diagonal represents how things could have turned out to be prior to our chemical investigations. It represents the space of conceptual possibility. The proposition that water is composed solely of hydrogen and oxygen, although necessarily true when our world is taken as actual, is only contingently true when each counterfactual world is taken as actual. It is metaphysically necessary, but conceptually contingent. Similarly, the proposition that water is composed solely of some chemical elements other than hydrogen and oxygen is necessarily false when our world is taken as actual, but only contingently false when each counterfactual world is taken as actual. It is metaphysically impossible, but conceptually 
contingent. Here's the two dimensional chart for the proposition that water is composed of some chemical elements other than $\mathrm{H} 2 \mathrm{O}$, namely XYZ:

\begin{tabular}{|c|l|l|l|l|}
\hline \multirow{2}{*}{$\#$} & \multicolumn{4}{|c|}{ World taken as Counterfactual } \\
\hline \multirow{4}{*}{$\begin{array}{c}\text { World taken as } \\
\text { actual }\end{array}$} & W1 & W1 & W2 & W3 \\
\cline { 2 - 6 } & W2 & F & F & F \\
\cline { 2 - 6 } & W3 & F & F & F \\
& & & T & T \\
\hline
\end{tabular}

\# Complete chart for the proposition that the actual watery substance is composed solely of chemical elements other than hydrogen and oxygen (i.e. water is composed solely of chemical elements other than hydrogen and oxygen)

Notice that it is conceptually possible that water is composed solely of chemical elements other than hydrogen and oxygen. That's represented by the fact that it is true in at least one position on the diagonal. But that conceptual possibility just is a metaphysical possibility characterized in a different way. The conceptual possibility of water being composed of something other than hydrogen and oxygen just is the metaphysical possibility of the watery stuff being composed of something other than hydrogen and oxygen. Although, in section 5, we will see some reason to reject this link between conceptual possibility and metaphysical possibility, for now let's just accept the link and see whether it will help us to develop a notion of philosophical conceivability.

\subsection{Two Conceptual Accounts of Conceivability}


Corresponding to the two kinds of possibility, there are two kinds of conceivability. ${ }^{19}$ Let's start with The Secondary Conceptual Account since that account corresponds directly, rather than indirectly, with metaphysical possibility:

The Secondary Conceptual Account:

$\mathrm{S}$ secondarily conceives that $\mathrm{P}$ iff $\mathrm{S}$ knows that $\mathrm{P}$ is consistent with all conceptual truths together with all truths which, when combined with conceptual truths, ampliatively entail necessary truths.

Let's call a truth which, when combined with conceptual truths, ampliatively entails necessary truths an "ampliative truth". Given Sophisticated Modal Conceptualism and The Secondary Conceptual Account, the fact that a proposition is consistent with all conceptual and ampliative truths is a partial grounds for the fact that it is possible and for the fact that it is secondarily conceivable. Hence, there is a tight explanatory connection between secondary conceivability and possibility and The Explanatory Constraint is met. Since something is possible because it is consistent with all conceptual and ampliative truths, if someone knows that it is consistent with all such truths, then she is in a position to know that it is possible. Hence, the Epistemic Constraint is met. And, finally, since knowledge entails truth, if someone knows that a proposition is consistent with all conceptual and ampliative truths, then it is in fact consistent with all such truths and hence, given

${ }^{19}$ The notions of conceivability expressed in this section is a simplified version of the notions developed and defended by Chalmers (2002). The names I have given to these accounts and to the corresponding notions of conceivability match the names used by Chalmers. Moreover, since Ichikawa and Jarvis (2012) focus primarily on conceptual coherence as a constraint on imagination, I tend to consider them defenders of a variety of the conceptual account. Finally, Menzies (1998) might also be considered a sort of conceptualist more broadly construed. Critics of the conceptual approach include Mizrahi and Morrow (2015), Roca-Royes (2011), and Yablo (2002) 
Sophisticated Modal Conceptualism, is possible. So, the view satisfies The Representational Constraint. $^{20}$

The Primary Conceptual Account is less straightforward. It corresponds directly with conceptual possibility and indirectly with metaphysical possibility:

The Primary Conceptual Account:

S primarily conceives that $\mathrm{P}$ iff and because $\mathrm{S}$ knows that $\mathrm{P}$ is consistent with all conceptual truths.

Let's start with The Representational Constraint. Recall that something is conceptually possible if it is consistent with all conceptual truths. So, since knowledge is factive, if someone primarily conceives that $\mathrm{P}$, then $\mathrm{P}$ is conceptually possible. But, since conceptual possibilities just are metaphysical possibilities differently characterized, it follows that $\mathrm{P}$, under a slightly different characterization, is metaphysically possible. So, The Primary Conceptual Account satisfies The Representational Constraint. ${ }^{21}$ Moreover, the fact that a proposition is conceptually consistent partially grounds that it is conceptually possible. But, again, conceptual possibility just is metaphysical possibility differently characterized and, so, the fact that a proposition is conceptually consistent also partially grounds that it is metaphysically possible, at least under some characterization. But, on the account above, conceptual consistency also partially grounds primary conceivability. Hence, there is a tight

\footnotetext{
${ }^{20}$ Moreover, we can say that S secondarily misconceives that P iff S reasonably believes that P is consistent with all conceptual truths together with all truths which, when combined with conceptual truths, ampliatively entail necessary truths even though $\mathrm{P}$ is not consistent with all such truths.

${ }^{21}$ We can say that $\mathrm{S}$ primarily misconceives that $\mathrm{P}$ iff S reasonably believes that $\mathrm{P}$ is consistent with all conceptual truths even though $\mathrm{P}$ is not consistent with all such truths.
} 
explanatory connection between primary conceivability and possibility and The Explanatory Constraint is met. Since something is possible, under one characterization, partly because it is consistent with all conceptual truths, if someone knows that it is consistent with all such truths, then she is in a position to know that it is possible. Hence, The Epistemic Constraint is met.

\section{Conceivability and The Modal Ontological Argument}

Recall the modal ontological argument from the introduction:

1. It's possible that God exists.

2. If it's possible that God exists, then God exists.

3. So, God exists.

One might reasonably believe the second premise given certain plausible modal principles and the assumption that, necessary, if God exists, then God necessarily exists. One might reasonably believe the first premise if one philosophically conceives that God exists, that is conceives that God exists in whatever sense, if any, generates reasonable belief in the possibility of what's conceived. Or if one philosophically conceives of something that otherwise supports the first premise.

We have three candidate notions of conceiving, The Fifth Imagination Account and The Primary and Secondary Conceptual Accounts, each one of which, arguably, satisfies at least the three constraints we have laid out for philosophical conceivability. Setting aside whether or not any of these three notions really is philosophical conceiving, can anyone 
conceive, in any of these four senses, that God exists or conceive of something that otherwise supports the first premise? I'm not sure. But I'll consider each of them in turn and see whether or not I can conceive that God exists or conceive of something that otherwise supports the first premise.

\subsection{Conceiving as Imagining and Premise (1)}

First, according to The Fifth Imagination Account:

$\mathrm{S}$ conceives that $\mathrm{P}$ iff (i) $\mathrm{S}$ aims to discover what is possible by way of imagination, (ii) S imagines a world, $\mathrm{w}$, such that $\mathrm{S}$ takes $\mathrm{w}$ to verify $\mathrm{P}$, where (iii) $\mathrm{P}$ is about the distribution of sensory qualities imagined in $\mathrm{w}$, and (iv) $\mathrm{P}$ is possible.

Certainly, I can aim to discover what is possible by way of imagination while imagining a world such that I take it to verify that there is a certain distribution of sensory qualities, a distribution as if there were authorities announcing the discovery of God in circumstances very similar to the actual circumstances. Since such a distribution of sensory qualities is possible, given the fourth imagination account, I would thereby be conceiving of such a distribution. And, finally, if The Fifth Imagination Account correctly characterizes philosophical conceivability, I would be reasonable in believing in the possibility of that distribution of sensory qualities. But how do I get from these facts to the possibility that God exists?

Here's one idea. Suppose I reasonably believe in the possibility of a distribution of sensory qualities as if there were authorities announcing the discovery of God in a 
circumstance very similar to the actual circumstance. Since the circumstance is very similar to the actual circumstance, then arguably I am reasonable in believing of that possible circumstance what I would be reasonable in believing if that possible circumstance had been actual. And, since I would be reasonable in believing that various authorities are announcing the discovery of God if that possible circumstance had been actual, I would be reasonable in believing that it's possible for authorities to announce the discovery of God. Finally, since I would be reasonable in believing that God exists if that possible circumstance had been actual, then I am reasonable in believing that possibly, God exists.

The problem is that I can also conceive of possible circumstances that similarly support, as reasonable, belief in the possibility that God does not exist. Since we are assuming that, necessarily, if God exists, then God necessarily exists, one of these beliefs is mistaken. Moreover, I can easily recognize that fact. When I recognize that I seem to reasonably believe both of two incompatible propositions and I have no reason to favor one of those beliefs over the other, then I ought to amend my attitude and instead suspend judgment. I am at a standoff with myself and, if The Fifth Imagination Account correctly characterizes philosophical conceivability, I see no way to break the standoff. ${ }^{22}$

\subsection{The Conceptual Accounts and Premise (1)}

\footnotetext{
22 Tidman (1994) presents a general problem for conceivability accounts of modal knowledge that he calls "the standoff problem". Tidman claims that anytime one can conceive that $\mathrm{P}$, one can also conceive that $\mathrm{P}$ is impossible and since one can easily recognize that the possibility of $\mathrm{P}$ and the possibility of the impossibility of $\mathrm{P}$ are incompatible, one cannot gain reasonable belief in the possibility of a proposition by conceiving it. I think Tidman is mistaken when he claims that anytime one can conceive that $\mathrm{P}$, one can also conceive that $\mathrm{P}$ is impossible. Remember that, given The Representation Constraint, a proposition cannot be conceivable unless it is genuinely possible. However, I do think that the particular standoff indicated above prevents one from supporting the second premise of the modal argument on the basis of imagination. But the standoff above occurs because of the gap that must be filled between what is conceived (a proposition about the distribution of sensory qualities) and the putative possibility under investigation (God's existence).
} 
Perhaps, though, there's better support for the first premise if we accept one of the conceptual accounts of conceivability. Consider The Secondary Conceptual Account:

$\mathrm{S}$ secondarily conceives that $\mathrm{P}$ iff and because $\mathrm{S}$ knows that $\mathrm{P}$ is consistent with all conceptual truths together with all truths which, when combined with conceptual truths, ampliatively entail necessary truths.

Recall that secondary conceivability entails metaphysical possibility on the assumption that Sophisticated Modal Conceptualism is correct. So, can I secondarily conceive that God exists?

Well, let me run though some of the things I think I know (or will assume I know) to see whether or not I know that God's existence is consistent with all conceptual truths together with all ampliative truths. First, I'll assume I know that Sophisticated Modal Conceptualism is correct. I'll also assume I know it neither follows from conceptual truths alone that God exists nor that God doesn't exist, i.e. it's neither a conceptual truth that God exists nor a conceptual truth that God does not exist. But, I also know that either it's necessary that God exists or it's necessary that God doesn't exist. So, one of those necessities, given Sophisticated Modal Conceptualism, must follow from some conceptual truth combined with an ampliative truth.

To make things simple, I'll assume it's a conceptual truth that if God exists, then God necessarily exists and, similarly, that it's a conceptual truth that if God doesn't exist, then, 
necessarily, God doesn't exist. ${ }^{23}$ So, if God exists, then that is an ampliative truth which, when combined with a conceptual truth just noted, entails that God necessarily exists. And if God does not exist, then that is an ampliative truth that, when combined with a conceptual truth just noted, entails that necessarily God does not exist. But the claim that God exists is clearly inconsistent with the claim that God does not exist. So, whether or not the proposition that God exists is consistent with all conceptual truths together with all ampliative truths depends on whether or not the proposition that God does not exist is an ampliative truth, and I know that fact. So, since I (let's suppose) have no idea whether or not God exists prior to considering the ontological argument, I have no idea whether or not God's existence is consistent with all conceptual truths together with all ampliative truths. Hence, I cannot secondarily conceive that God exists. Moreover, even if I could come to know that God exists and, hence, come to know that God's existence is consistent with all conceptual truths together with all ampliative truths, thereby secondarily conceiving that God exists, no such conceiving could unobjectionably be used as partial support for the modal ontological argument. So what about the primary conceptual account?

\footnotetext{
${ }^{23}$ Things can get very complicated. Presumably if Sophisticated Modal Conceptualism is true, then it is a conceptual truth. But it seems like a conceptual truth, also, that if Sophisticated Modal Conceptualism is true, then it is necessary that if God exists, then there is some truth, T, such that if T, then God necessarily exists. It follows that it is a conceptual truth that it's necessary that if God exists then there is some truth, T, such that if $\mathrm{T}$, then God necessarily exists. But the embedded necessary conditional must either be a conceptual truth itself or follow from some conceptual truth together with an ampliative truth. Honestly, I can't say for certain that the latter option isn't correct, but the former option just seems far more plausible. So, let's suppose it is a conceptual truth that if God exists, then there is some truth, T, such that if T, then God necessarily exists. It follows by simple conceptual truths of logic that if God exists, then God necessarily exists. So, it is a conceptual truth that if God exists, then God necessarily exists. A similar argument can show that it is a conceptual truth that if God doesn't exist, then it's necessary that God doesn't exist.
} 
$\mathrm{S}$ primarily conceives that $\mathrm{P}$ iff and because $\mathrm{S}$ knows that $\mathrm{P}$ is consistent with all conceptual truths.

I am assuming I know that it is neither a conceptual truth that God exists nor a conceptual truth that God doesn't exist. So, I can know that the proposition that God exists is consistent with all conceptual truths and, hence, I can primarily conceive that God exists. But remember that the route from primary conceivability to metaphysical possibility is not straightforward. What I can reasonably believe on the basis of my conceiving is that the proposition that God exists is conceptually possible. Given the assumption that conceptual possibilities just are metaphysical possibilities characterized in a different way, the proposition that God exists is metaphysically possible when differently characterized. However, I will argue against that assumption and, hence, block any support for the first premise by way of primary conceivability; primary conceivability, if I am right, cannot be philosophical conceivability.

As I noted above, if I know that it is neither a conceptual truth that God exists nor a conceptual truth that God doesn't exist, I can primarily conceive that God exists. But I can also, then, primarily conceive that God doesn't exist. What is it that I am conceiving and how, if at all, are such conceivings linked to metaphysical possibility? Well, let's follow our watery example and assume the proposition that God exists just is the descriptive proposition that the actual essentially unsurpassable necessary being exists and the proposition that God doesn't exist just is the descriptive proposition that the actual essentially unsurpassable necessary being doesn't exist. Using the apparatus of possible worlds and assuming, for reductio, that conceptual possibilities are metaphysical 
possibilities differently characterized, it follows that there is a world taken as actual at which there is an essentially unsurpassable necessary being. But, then, the being which at that world is an essentially unsurpassable necessary being must, being a necessary being, exist at each other world and must, being an essentially unsurpassable being, be unsurpassable at each other world as well. But that means that no matter what world is taken as actual, there will be an essentially unsurpassable necessary being there. Things seem to be looking good for premise (1)! But, recall, the proposition that the actual essentially unsurpassable necessary being doesn't exist is also conceptually possible. So, there must be some world taken as actual at which there is no such being. But it cannot be both that no matter what world is taken as actual, there will be an essentially unsurpassable necessary being there and there is some world taken as actual at which there is no such being. Hence, contrary to our assumption, some conceptual possibilities do not characterize metaphysical possibilities. ${ }^{24}$

I see three options available to the defender of primary conceivability as philosophical conceivability, none of which will help the defender of the modal ontological argument. First, one can say that it is neither primarily conceivable that God exists nor that God doesn't exist. On this option, since it is either necessary that God exists or necessary that God doesn't exist, given Sophisticated Modal Conceptualism, one of those two facts must follow from an ampliative truth and, hence, we must fall back on secondary conceivability. But we've already seen that secondary conceivability doesn't seem to help us support premise (1).

\footnotetext{
${ }^{24}$ This problem did not arise in our watery case because the descriptive content associated with water did
} not contain the concept of necessity or essentiality. 
Second, one can say that it is either primarily conceivable that God exists or that God doesn't exist, but that it is not both. If one of those propositions is not primarily conceivable, then that proposition is inconsistent with some conceptual truth. And if one of those propositions is inconsistent with some conceptual truths, then its negation follows from conceptual truths alone and, hence, is itself a conceptual truth. So, either it is a conceptual truth that God exists or it is a conceptual truth that God doesn't exist. So, whether or not God exists will have to be determined by conceptual analysis before any primary conceiving can occur and, hence, no such conceiving could unobjectionably be used as partial support for the modal ontological argument.

Finally, one might claim that the concept of being unsurpassable is itself descriptive and whereas one thing might be essentially unsurpassable when one possibility is taken as actual it is not unsurpassable at all, much less essentially unsurpassable, when another world is taken as actual. In that case, although we might be able to conceive of an essentially unsurpassable necessary being, we have no reason to believe that, when our world is taken as actual, it is an unsurpassable being. In other words, what we conceive when we conceive of an essentially unsurpassable necessary being characterizes a metaphysical possibility, but not the possibility of an essentially unsurpassable necessary being. Hence, our primary conceiving does not support premise (1). ${ }^{25,26}$

\footnotetext{
${ }^{25}$ Similarly, we might think that what is necessary and what is essential depends on which world is taken as actual. In that case, although we might be able to conceive of an essentially unsurpassable necessary being, when our world is taken as actual, it is a necessary or essentially unsurpassable being. This option has the same problems as the one just discussed.

26 Thanks to the members of my fall 2015 seminar on conceivability and possibility for many helpful discussions and for reading an early draft of this paper. Thanks to Stan Husi and Kris McDaniel for reading and commenting on early drafts of this paper. And special thanks to Fabrizio Mandadori who extensively discussed these issues with me throughout the 2015/2016 academic year. Fabrizio's insights on this topic are extensive and I am afraid that I cannot do this topic the kind of justice it deserves in a short essay.
} 


\section{Bibliography}

Aquinas Expositio Super Librum Boethii De Trinitate, q. 4, a. 3, ad 1 (p. 151)

Ayer, Alfred Jules (1936) Language, Truth and Logic. London: Victor Gollancz Ltd., 1946. Second edition.

Chalmers, David J. (2002) “Does Conceivability Entail Possibility?” In Tamar S. Gendler \& John Hawthorne (eds.), Conceivability and Possibility. Oxford University Press 145-200.

Gendler, Tamar Szabó \& John Hawthorne (2002). "Introduction: Conceivability and Possibility." In T. Szabó Gendler \& John Hawthorne (eds.), Conceivability and Possibility. Oxford University Press 1--70.

Gregory, Dominic (2010) “Conceivability and apparent possibility.” In Modality: Metaphysics, Logic, and Epistemology eds. Bob Hale and Aviv Hoffman (OUP)

Hartshorne, Charles (1965) Anselm's Discovery: A Re-Examination of the Ontological Proof for God's Existence. La Salle, IL: Open Court.

Ichikawa, Jonathan \& Benjamin Jarvis (2012) “Rational Imagination and Modal Knowledge", Noûs 46 (1):127 - 158.

Kripke, Saul (1971) "Identity and Necessity," in Identity and Individuation, Milton K. Munitz (ed.), New York, New York University Press, pp. 135-164.

Kripke, Saul (1980) Naming and Necessity. Cambridge: Harvard University Press.

Kung, Peter (2010) "Imagining as a Guide to Possibility", Philosophy and Phenomenological Research 81 (3):620-663.

----- (2016) “You Really Do Imagine It: Against Error Theories of Imagination”, Noûs 50 (1):90-120.

Malcolm, Norman (1960) “Anselm's Ontological Arguments”, Philosophical Review, 69: 4162.

Menzies, Peter (1998). "Possibility and Conceivability: A Response-Dependent Account of Their Connections.” In Roberto Casati (ed.), European Review of Philosophy, Volume 3: Response-Dependence. Stanford: Csli Publications 255--277.

Mizrahi, Moti \& David R. Morrow (2015). “Does Conceivability Entail Metaphysical Possibility?" Ratio 28 (1):1-13. 
Oppy, Graham (1995) Ontological Arguments and Belief in God, New York: Cambridge University Press.

----- (2016) "Ontological Arguments", The Stanford Encyclopedia of Philosophy (Spring 2016 Edition), Edward N. Zalta (ed.), URL = <http://plato.stanford.edu/archives/spr2016/entries/ontological-arguments/>.

Plantinga, Alvin (1974) The Nature of Necessity, Oxford: Oxford University Press.

Putnam, Hilary (1975). "The Meaning of 'Meaning'”. Minnesota Studies in the Philosophy of Science 7:131-193.

Roca-Royes, Sonia (2011). “Conceivability and De Re Modal Knowledge.” Noûs 45 (1):2249.

Sidelle, Alan (1989) Necessity, Essence, and Individuation. Ithaca: Cornell University Press.

Sider, Theodore (2003) "Reductive Theories of Modality." In Michael J. Loux \& Dean W. Zimmerman (eds.), The Oxford Handbook of Metaphysics. Oxford University Press. 180-208.

Scotus Lectura II, Dist. 3, pars. 1, Q 5-6, n. 180.

Sorensen, Roy (2006) "Meta-conceivability and Thought Experiments," The Architecture of the Imagination: New Essays on Pretence, Possibility and Fiction. ed. Shaun Nichols. Oxford: OUP.

Tidman, Paul (1994). "Conceivability as a Test for Possibility." American Philosophical Quarterly 31 (4):297-309.

Yablo, Stephen (1993) “Is Conceivability a Guide to Possibility?" Philosophy and Phenomenological Research 53 (1):1-42.

----- (2002). “Coulda, Woulda, Shoulda.” In Tamar S. Gendler \& John Hawthorne (eds.), Conceivability and Possibility. Oxford University Press 441-492.

van Inwagen, Peter (1977) “Ontological Arguments”, Noûs, 11: 375-395.

----- (1998) “Modal Epistemology.” Philosophical Studies 92 (1):67--84.

---- (2015) Metaphysics, Westview Press. 